\title{
Fabrication and Characterization of Graphene/Epoxy Nanocomposites
}

\author{
Shiuh Chuan HER *, Lei Yao CHEN \\ Department of Mechanical Engineering, Yuan Ze University, Taiwan \\ crossref http://dx.doi.org/10.5755/j01.ms.25.4.19462
}

Received 10 November 2017; accepted 14 August 2018

\begin{abstract}
Graphene with high electric and thermal conductivities has been widely used as reinforced filler. In this study, graphene loadings in the range between 0.3 and $1.0 \mathrm{wt} . \%$ were added to the epoxy to fabricate the nanocomposites. The mechanical and thermal properties of nanocomposites were characterized using tensile test and differential scanning calorimeter (DSC), respectively. Experimental results show that the elastic modulus, yield strength, ultimate strength and glass transition temperature of the graphene reinforced epoxy are increasing with the increase of the graphene, while the fracture strain and toughness are decreasing with the increase of the graphene. Scanning electron microscope (SEM) was employed to investigate the dispersion and separation of graphene in the epoxy based matrix. The SEM images depict that graphene is well dispersed resulting in a significant improvement of the mechanical and thermal properties of the nanocomposites. The mechanical properties and thermal stability of epoxy nanocomposites with graphenes and multiwalled carbon nanotubes additives were then compared. Experimental results show that nanocomposite with graphene additives outperform the multi-walled carbon nanotube additives.

Keywords: graphene, nanocomposite, tensile strength, glass transition temperature.
\end{abstract}

\section{INTRODUCTION}

Graphene, a novel carbon material with a twodimensional layer and single atom thickness, has received a great attention from both scientists and engineers due to its excellent mechanical and electrical properties. Theoretical prediction and experimental results show that graphene exhibits excellent properties of Young's modulus $1000 \mathrm{GPa}$, fracture toughness $125 \mathrm{GPa}$ [1], thermal conductivity $5000 \mathrm{~W} / \mathrm{mK}$ [2], electron charge mobility $200,000 \mathrm{~cm}^{2} / \mathrm{V}[3]$ and electrical conductivity $10^{-6} \Omega^{-1} \mathrm{~cm}^{-1}$ [4]. These properties make graphene an ideal candidate for many potential applications such as solar cells and hydrogen storage [5], sensors [6], batteries [7] and supercapacitors [8]. Graphene nanoplatelets (GNPs) composed of multiple graphene layers that are stacked together have similar properties as those of single layer graphene. However, GNPs are much easier to fabricate and hold in comparison with single-layer graphene [9]. In addition, the performance of GNP is better than that of carbon nanotube (CNT) based on the following reasons: the abundance of GNPs in nature yields in a reduce of the cost; the high specific surface area of GNPs leads to a higher degree of stress being transferred across the interface and GNPs provides a better reinforcement then that of CNTs [10].

Nanocomposites are considered as a new class of composites incorporated with nano scale reinforcements that are well dispersed in a polymer matrix. The nano scale fillers can improve the interfacial interaction, leading to the superior properties of nanocomposites in comparison with conventional composites [11]. Recently, polymer-based nanocomposites reinforced with graphenes have attracted widespread industrial interest because graphene has a great

\footnotetext{
* Corresponding author. Tel.: +886-3-4638800; fax: +886-3-4558013

E-mail address: mesch@saturn.yzu.edu.tw (S.H. Her)
}

capability of enhancing the electrical conductivity and mechanical properties of the nanocomposites [12]. Epoxy resin is one of the most commonly used polymers, due to its extremely high fracture toughness and mechanical stiffness, chemical resistance and good solvability, and better adhesion [10]. Moriche et al. [13] investigated the electrical behavior and mechanical properties of epoxybased nanocomposites reinforced with functionalized graphene nanoplatelets. They found that the electrical conductivity of nanocomposites with GNPs of 12 wt.\% was in the range of $10^{-4} \mathrm{~S} / \mathrm{m}$, and reported that the flexural strength increased by $11 \%$. Dai and Mishnaevsky [14] developed a three dimensional model of polymer-based composites reinforced with graphenes to study the influence of nano fillers, such as the volume fraction, shape, aggregation, orientation and aspect ratio of graphene nanoplatelets on the mechanical properties and failure mechanisms of nanocomposites. They found that the elastic modulus of the nanocomposites increases with the increased volume fraction, aspect ratio, interfacial properties between the polymer and graphene, and as the degree of interaction decreased. The ultimate strength exhibits similar trends, except for the aspect ratio and aggregation, where the opposite tendencies were reported. Wan et al. [15] prepared epoxy nanocomposites with homogeneously dispersed graphene using a facile surfactant-assisted process, and the tensile strength of the nanocomposite was significantly increased by $57 \%$ at $0.1 \%$ weight loading. Luong et al. [16] studied the incorporation of $0.38 \mathrm{wt} . \%$ of functionalized graphene in a polyimide nanocomposite and showed that the elastic modulus increased by an approximately $30 \%$. Zaman et al. [17] fabricated epoxy-based nanocomposites with chemical modification of graphene nanoplatelets to study the influence of the interfacial interaction on the microstructure and properties of the nanocomposites. They found that the strain energy release rate of the 
nanocomposite reinforced with 4 wt. $\%$ of chemical modification GNPs was $96.1 \%$ greater than the strain energy release rate of unmodified GNP. The glass transition temperature of the nanocomposite with $2.5 \mathrm{wt} . \%$ GNP was $108.6^{\circ} \mathrm{C}$, while the glass transition temperature of the neat epoxy was $94.7^{\circ} \mathrm{C}$. Pontefisso and Mishnaevsky [18] proposed a computational model to investigate the influence of microstructure, shapes and dispersion of carbon nanotubes and graphene in polymers on fracture resistance and tensile strength. Zarasvand and Golestanian [19] employed theoretical, numerical and experimental methods to study the effects of the number of layers, orientation and dispersion of GNP on the mechanical properties of nanocomposites reinforced with graphene. Spanos and Anifantis [20] developed a micromechanical hybrid finite element model to investigate the capability of stress transfer in nanocomposites reinforced with graphene. They found that stress transfer between the graphene and polymer matrix is significantly dependent on the volume fraction, polymer matrix and interfacial interaction. Liu et al. [21] designed a sandwich structure to directly measure the interfacial shear strength between polymethyl methacrylate and graphene nanoplatelets.

Jangam et al. [22, 23] investigated the effect of multiwalled carbon nanotube alignment on the mechanical, electrical and vibrational properties of nanocomposites. They found that the alignment of MWCNTs has improved the modal damping by $37 \%$, electrical conductivity by $200 \%$. and fatigue life by $15 \%$ with a small weight percentage of MWCNT loading (wt.\%<0.5\%) into the epoxy matrix. Sethi et al. [24] examined the role of aspect ratio and length of MWCNTs in determining the performance of nanocomposites. They observed that the electrical properties were proportional to length of the MWCNTs whereas the mechanical properties were dependent on the aspect ratio of the MWCNTs. Liang [25] studied the effects of graphene nanoplatelets size and content on tensile properties of polypropylene composites. Bansal et al. [26] demonstrated a promising way to improve the elastic modulus, hardness and fracture resistance simultaneously by reinforcing the epoxy (bisphenol-A) matrix with a new-age two-dimensional thin graphene oxide sheet. High improvements were observed by Zakaria et al. [27] when 1 wt.\% GNPs were integrated within the epoxy system. The tensile and flexural strength of GNP nanocomposites improved up to $26 \%, 29 \%$ respectively, compared to the neat epoxy. Epoxy-based nanocomposites have been extensively used for mechanical strength applications such as aerospace, automobiles and marine industries due to their light weight, better strength and ease of processing [26].

Many researchers have investigated the effects of reinforcing nanocomposite with either MWCNT or GNP. However, few works have studied and compared the performance between the MWCNT and GNP reinforced nanocomposites [28, 29]. The novelty of this study is that nanocomposites reinforced with both MWCNTs and GNPs were fabricated and characterized. In this work, epoxy nanocomposites reinforced with graphene nanoplatelets and multi-walled carbon nanotubes (MWCNTs) were prepared at various weight fractions ranging from $0.3 \%$ to
$1.0 \%$. The mechanical properties of nanocomposites including the elastic modulus, ultimate strength and strain at break were obtained by tensile testing. The glass transition temperature of nanocomposites was measured by differential scanning calorimeter (DSC). The mechanical and thermal properties of epoxy-based matrix with GNPs and MWCNTs additives were compared.

\section{PREPARATION OF EPOXY NANOCOMPOSITES}

\subsection{Materials}

Both the graphene nanoplatelets and multi-walled carbon nanotubes were purchased from Uchess Co. Taiwan. The GNPs had thickness ranging from 1 to $10 \mathrm{~nm}$, length ranging $0.5-20 \mu \mathrm{m}$, specific surface area $40-60 \mathrm{~m}^{2} / \mathrm{g}$ and a purity of $>99.5 \mathrm{wt} . \%$. The diameter of MWCNTs is in the range between $40 \sim 60 \mathrm{~nm}$, while the length is $5-10 \mu \mathrm{m}$ and a purity of $>95 \mathrm{wt} . \%$. The matrix used in this work consisting of part A: epoxy Mungo 4200A and part B: hardener Mungo 4200B, was provided by Golden Root Co., Ltd Taiwan. Deionized water was employed in all processes if necessary. The morphologies of pristine GNPs and MWCTNs were examined using scanning electron microscopy (SEM) as shown in Fig. 1.

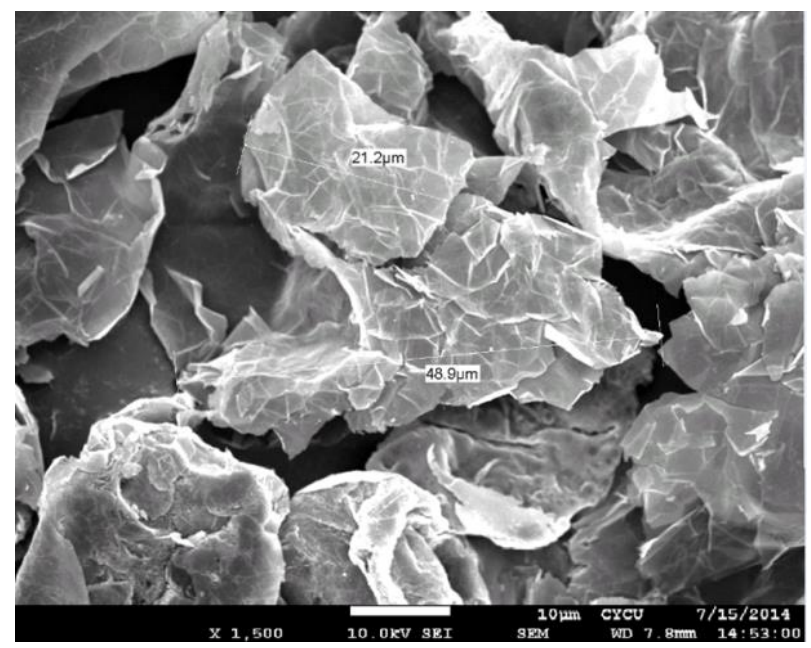

a

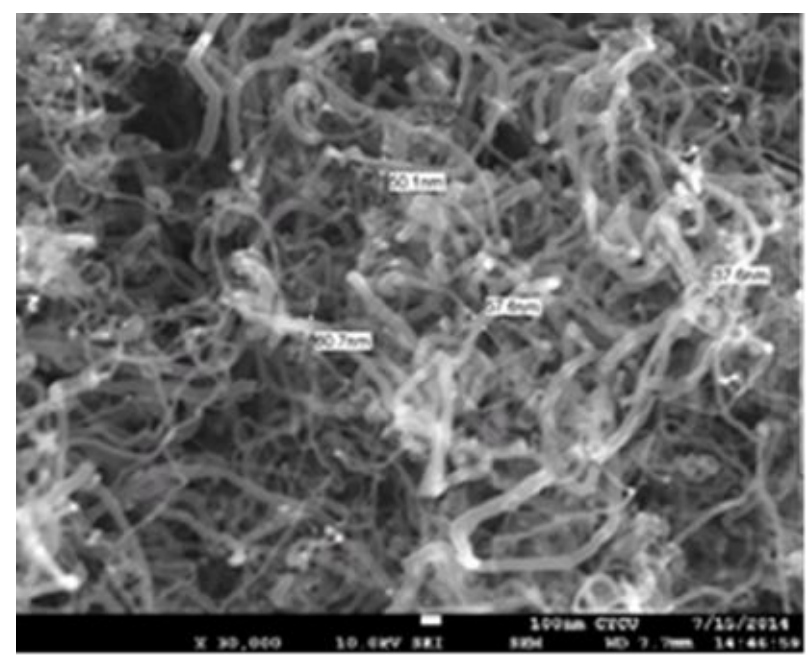

b

Fig. 1. SEM images: $a$-pristine GNPs; $b$-MWCNTs 


\subsection{Fabrication of GNP/epoxy nanocomposites}

Epoxy-based nanocomposites reinforced with different weight loadings of GNPs and MWCNTs were fabricated using the following procedures. A desired concentration of GNPs or MWCNTs was first dispersed in ethanol and sonicated in an ultrasonic bath for $30 \mathrm{~min}$ at temperature of $40{ }^{\circ} \mathrm{C}$. Then the suspension was poured into a liquid epoxy that was preheated at a temperature of $40{ }^{\circ} \mathrm{C}$ for 30 minutes. The solution was further processed with mechanical stirring and sonicating for 3 hours to separate the aggregation of nanofillers (GNPs or MWCNTs) and achieve good dispersion. The dispersions were degassed in a vacuum chamber maintained at pressure of $20 \mathrm{mmHg}$ for $30 \mathrm{~min}$ to remove the ethanol, followed by addition of the hardener with a resin-to-hardener weight ratio of 2:1 and softly stirred it for about 10 minutes. Afterwards the mixture was placed in a vacuum chamber for about $30 \mathrm{~min}$ to remove the bubbles induced from the stirring. After degassing, the blend was poured into a dog-bone-like aluminum mold to fabricate the tensile test specimen. The specimen was cured in a vacuum oven at a temperature of $40{ }^{\circ} \mathrm{C}$ for 24 hours. Samples of neat epoxy, GNPs/Epoxy and MWCNTs/Epoxy were prepared in the same procedures. Three samples were prepared for each concentration. The experimental results reported in this work are the averaged values. The standard deviation is also provided to demonstrate the consistency of the experimental tests.

\subsection{Characterization and instruments}

The dispersion of GNPs and MWCNTs in epoxy was characterized by a field emission-scanning electron microscope (FE-SEM, Joel JSM-7600F, Japan) with an accelerating potential of $10.0 \mathrm{kV}$. The mechanical properties of the nanocomposites were obtained by uniaxial tensile test using a Hounsfield Model 10KS universal test machine according to the ASTM standard D638. The thermal stability of epoxy nanocomposites was determined by differential scanning calorimeter (DSC) measurements performed on a Mettler Toledo DSC 1 under a nitrogen atmosphere. Each sample (about $4 \mathrm{mg}$ ) was heated from -10 to $200{ }^{\circ} \mathrm{C}$ at a heating rate of $10^{\circ} \mathrm{C} / \mathrm{min}$.

\section{RESULTS AND DISCUSSION}

\subsection{Mechanical properties}

Uniaxial tensile tests were performed to evaluate the mechanical properties of neat epoxy, GNPs/epoxy and MWCNTs/epoxy nanocomposites with various weight fractions ranging from $0.3 \%$ to $1.0 \%$ under the loading rate of $1 \mathrm{~mm} / \mathrm{min}$. To ensure the reproductivity of the results, three samples of each group were prepared and tested. The results presented in this study are the average values of these samples. The stress and strain relationships for neat epoxy and epoxy reinforced with GNPs at various contents ranging from $0.3 \mathrm{wt} . \%$ to $1 \mathrm{wt} . \%$ are plotted in Fig. 2. The figure shows that both the elastic modulus and tensile strength of GNP/epoxy are higher than that of neat epoxy. However, the fracture strain of GNP/epoxy exhibits in the opposite trend which is decreasing with the increase of the GNP loading. The numerical values of elastic modulus, yielding stress, ultimate tensile strength, fracture strain and fracture modulus are presented in Table 1. The elastic modulus $(2.80 \mathrm{GPa})$ of GNPs/Epoxy nanocomposite with $1 \%$ weight fraction is about $40.7 \%$ larger than the neat epoxy $(1.99 \mathrm{GPa})$. Incorporation of $1 \%$ weight fraction of GNPs increases the tensile strength of the neat epoxy by $25.8 \%$ from $40.29 \mathrm{MPa}$ to $50.67 \mathrm{MPa}$. At the same time, the fracture strain of the neat epoxy decreased by $33.7 \%$ from 0.0418 to 0.0277 as the concentration of GNPs increases to $1 \mathrm{wt} . \%$. The elastic modulus and ultimate strength are significantly improved with a comprised fracture strain. The results also show that the stiffness and strength of the epoxy are increased as the concentration of GNPs increased while the ductility is reduced as the GNPs increased. The increase in the elastic modulus and ultimate strength of the GNPs/Epoxy nanocomposites could be related to the uniform dispersion of GNPs and its anisotropic orientation in epoxy matrix, resulting in an efficient stress transfer from epoxy matrix to the nanofillers.

Fig. 3 plots the stress and strain relationships of MWCNTs/epoxy nanocomposites with different MWCNT loadings varying between 0.3 and $1 \mathrm{wt} . \%$. The elastic modulus, yielding stress, ultimate tensile strength, fracture strain and fracture modulus of nanocomposites can be determined from the stress and strain relationships as listed in Table 2. In particular, the table shows that both the elastics modulus and ultimate tensile strength increase as the MWCNT loading increased, while the fracture strain and fracture modulus decrease as the MWCNT loading increased. The elastic modulus of the MWCNT reinforced epoxy increased from $1.99 \mathrm{GPa}$ to $2.40 \mathrm{GPa}$ as the MWCNT loading increased from $0 \%$ to $1.0 \mathrm{wt} \%$. In addition, the ultimate tensile strength of the MWCNT reinforced epoxy increased from 40.29 $\mathrm{MPa}$ to $48.87 \mathrm{MPa}$ as the MWCNT loading increased from $0 \%$ to $1.0 \mathrm{wt} . \%$. Meanwhile, the elongation at break decreased from $4.18 \%$ to $3.49 \%$ as the MWCNT loading increased from $0 \%$ to $1.0 \mathrm{wt} . \%$.

Table 1. The averaged values of the mechanical properties of GNPs/Epoxy nanocomposites with different weight fractions of GNPs

\begin{tabular}{|l|c|c|c|c|c|}
\hline \multicolumn{1}{|c|}{ Weight fraction } & $0 \%$ & $0.3 \%$ & $0.5 \%$ & $0.8 \%$ & $1 \%$ \\
\hline Mechanical properties & \multirow{2}{*}{$0.99 \pm 0.02$} & $2.23 \pm 0.01$ & $2.42 \pm 0$ & $2.64 \pm 0.03$ & $2.8 \pm 0.05$ \\
\hline Young's modulus, GPa & $31.18 \pm 0.27$ & $34.89 \pm 0.18$ & $35.46 \pm 0.91$ & $36.29 \pm 0.05$ & $37.86 \pm 0.46$ \\
\hline Yield stress, MPa & $40.29 \pm 0.13$ & $44.23 \pm 0.29$ & $45.13 \pm 0.17$ & $49.49 \pm 0.38$ & $50.67 \pm 0.47$ \\
\hline Tensile strength, MPa & $0.0418 \pm 0.0007$ & $0.0333 \pm 0.0026$ & $0.031 \pm 0.0025$ & $0.0298 \pm 0.0015$ & $0.0277 \pm 0.0009$ \\
\hline Fracture strain & $1.18 \pm 0.01$ & $1.05 \pm 0.02$ & $1.02 \pm 0.01$ & $0.96 \pm 0.06$ & $0.86 \pm 0.06$ \\
\hline Fracture modulus, MPa & & & &
\end{tabular}


Table 2. The averaged values of the mechanical properties of MWCNTs/Epoxy nanocomposites with different weight fractions of MWCNTs

\begin{tabular}{|l|c|c|c|c|c|}
\hline \multicolumn{1}{|c|}{ Weight fraction } & $0 \%$ & $0.3 \%$ & $0.5 \%$ & $0.8 \%$ & $1 \%$ \\
\hline Mechanical properties & $1.99 \pm 0.02$ & $2.17 \pm 0.01$ & $2.27 \pm 0.02$ & $2.34 \pm 0.02$ & $2.40 \pm 0.01$ \\
\hline Young's modulus, GPa & $31.18 \pm 0.27$ & $33.55 \pm 0.22$ & $34.20 \pm 0.03$ & $35.78 \pm 0.27$ & $36.69 \pm 0.22$ \\
\hline Yield stress, MPa & $40.29 \pm 0.13$ & $44.66 \pm 0.14$ & $45.26 \pm 0.2$ & $47.42 \pm 0.27$ & $48.87 \pm 0.15$ \\
\hline Tensile strength, MPa & $0.0418 \pm 0.0007$ & $0.0401 \pm 0.0001$ & $0.0384 \pm 0.0003$ & $0.0355 \pm 0.0002$ & $0.0349 \pm 0.0001$ \\
\hline Fracture strain & $1.18 \pm 0.01$ & $1.27 \pm 0.01$ & $1.22 \pm 0.02$ & $1.15 \pm 0.01$ & $1.16 \pm 0.01$ \\
\hline Fracture modulus, MPa & & &
\end{tabular}

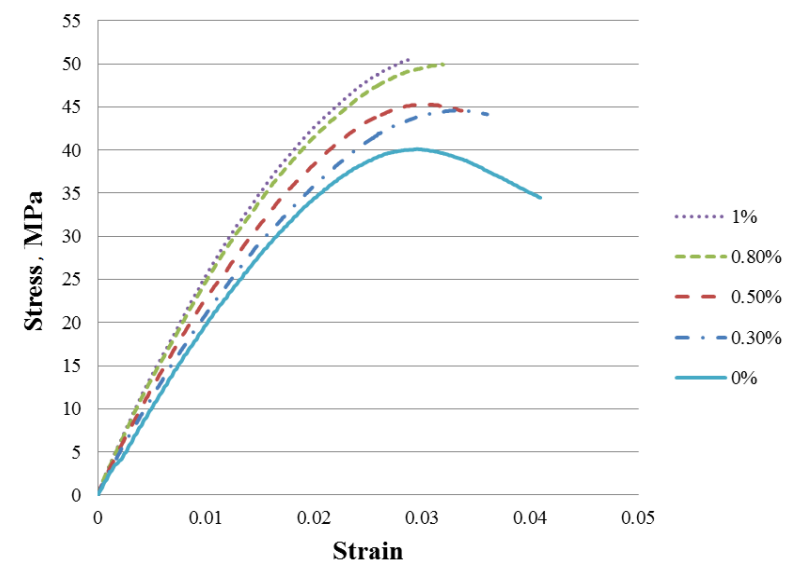

Fig. 2. Stress and strain relationships for GNPs/epoxy nanocomposites with different weight fractions of GNPs

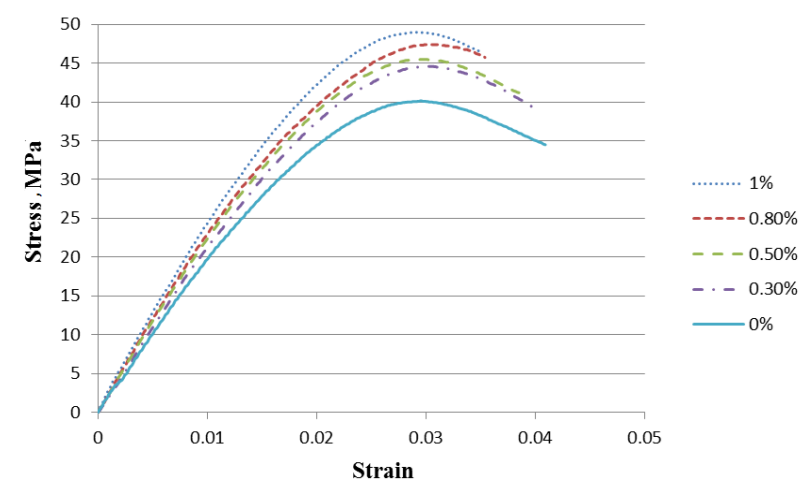

Fig. 3. Stress and strain relationships for MWCNTs/epoxy nanocomposites with different weight fractions of MWCNTs

Graphene can be used to generate a variety of carbonbased nanostructures. For example, a single layer of graphene can be rolled up to construct a single-walled carbon nanotube (SWCNT). Multiple graphene layers are rolled up to form multiple concentric SWCNTs with the same axis comprising multi-walled carbon nanotube (MWCNT). All the above carbon-based nanostructures exhibit excellent mechanical properties (such as elastic modulus and ultimate tensile strength) due to the $\mathrm{sp}^{2}$ carbon bonding network. The aim of this work is to invetigate which of these nanofillers has the best performence of transferring their mechanical properties to the polymer-based nanocomposites. To examine this, we compared the elastic modulus, yielding stress, ultimate tensile strength, and fracture strain of GNPs/Epoxy and MWCNTs/Epoxy nanocomposites for various weight fractions ranging from $0.3 \%$ to $1.0 \%$, as shown in Fig. 4 , Fig. 5, Fig. 6, and Fig. 7, respectively.

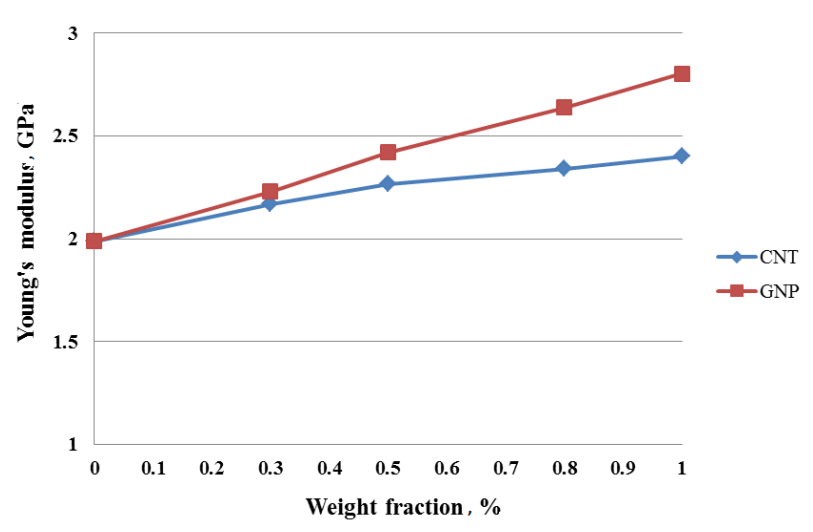

Fig. 4. Comparison of Young's modulus between GNPs/Epoxy and MWCNTs/epoxy nanocomposites with various weight fractions

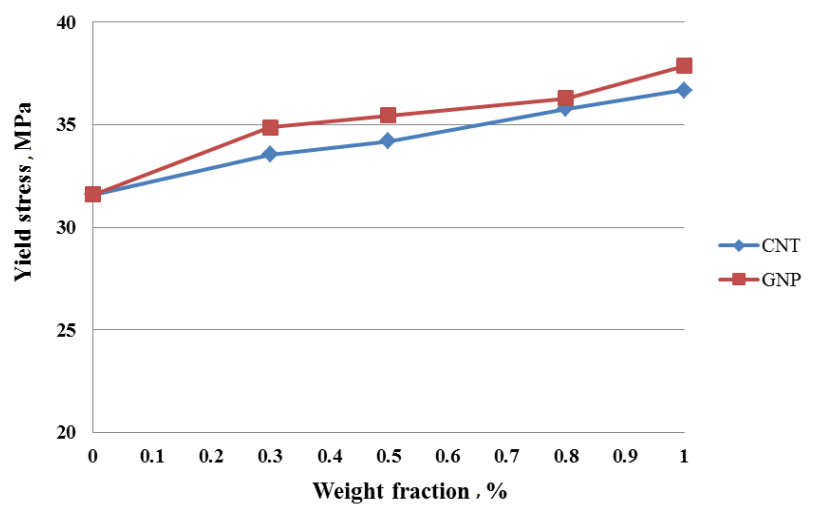

Fig. 5. Comparison of yield stress between GNPs/Epoxy and MWCNTs/epoxy nanocomposites with various weight fractions

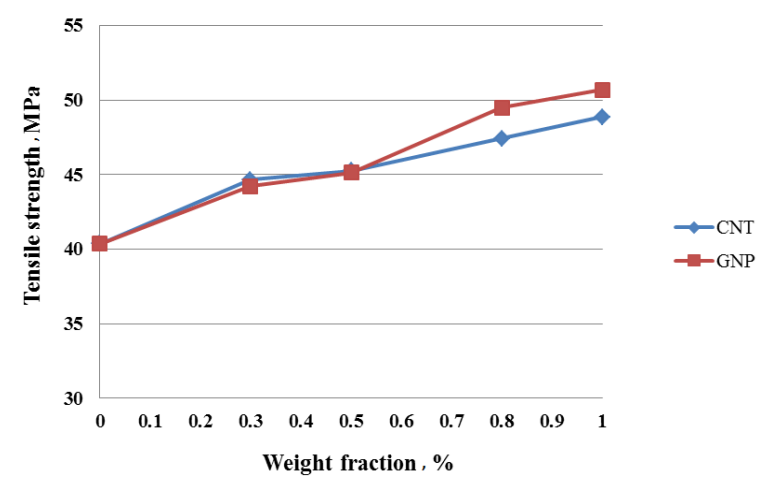

Fig. 6. Comparison of tensile strength between GNPs/Epoxy and MWCNTs/epoxy nanocomposites with various weight fractions

Experimental results indicate that the elastic modulus, yielding stress and ultimate tensile strength of the GNPs/Epoxy nanocomposite are higher than that of 
MWCNTs/Epoxy nanocomposite, while the fracture strain is lower than that of the MWCNTs/Epoxy nanocomposite. It can be observed that the capability of GNPs in strengthening the nanocomposite is clearly superior to MWCNTs. The better performance of GNPs over MWCNTs in terms of mechanical properties could be attributed to the high specific surface area resulting in an improvement of nanofiller-matrix adhesion and interlocking. The reinforcement effect of the GNP fillers is the good interfacial interactions between GNPs and epoxy macromolecules.

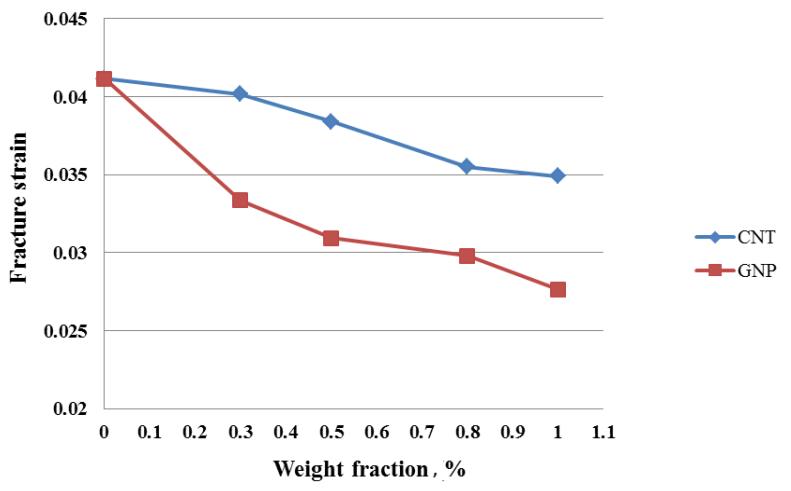

Fig. 7. Comparison of fracture strain between GNPs/Epoxy and MWCNTs/epoxy nanocomposites with various weight fractions

\subsection{Fracture surface morphology}

To better understand the enhancement of mechanical properties of GNPs/Epoxy nanocomposites, the morphologies of the fractured surfaces of neat epoxy and GNPs/Epoxy nanocomposites were examined using SEM. Figure 10 shows the SEM images of the fractured surfaces. It can be seen that neat epoxy possesses a smooth fractured surface as illustrated in Fig. 8 a. In comparison, the GNPs/Epoxy nanocomposites with 0.3 wt.\%, 0.5 wt. $\%$ and $1.0 \mathrm{wt} . \%$ of graphene contents exhibit rough fractured surfaces as shown in Fig. $8 \mathrm{~b}-\mathrm{d}$, and this can be attributed to the strong interfacial adhesion and good compatibility between the epoxy matrix and GNPs. Such strong interfacial adhesion is in favor of the stress transfer from the epoxy matrix to the graphene, resulting in an improvement of the Young's modulus and tensile strength of the nanocomposites while compares with those of the neat epoxy. Another important factor concerning the reinforcement effect of the GNPs is the better dispersion of the GNPs in the epoxy matrix as shown in Fig. $8 \mathrm{~b}-\mathrm{d}$, than the dispersion of the MWCNTs as shown in Fig. 9.

\subsection{Thermal property}

Differential scanning calorimeter (DSC) can be used to study the thermal stability of carbon-based materials and the relative information of the molecules that are grafted to the graphene. In this work, the influences of the GNPs and MWCNTs on the glass transition temperature $\left(T_{g}\right)$ of epoxy-based nanocomposites were investigated by DSC. The DSC thermograms of the GNPs/Epoxy and MWCNTs/Epoxy nanocomposites are shown in Fig. 10 and Fig. 11, respectively.

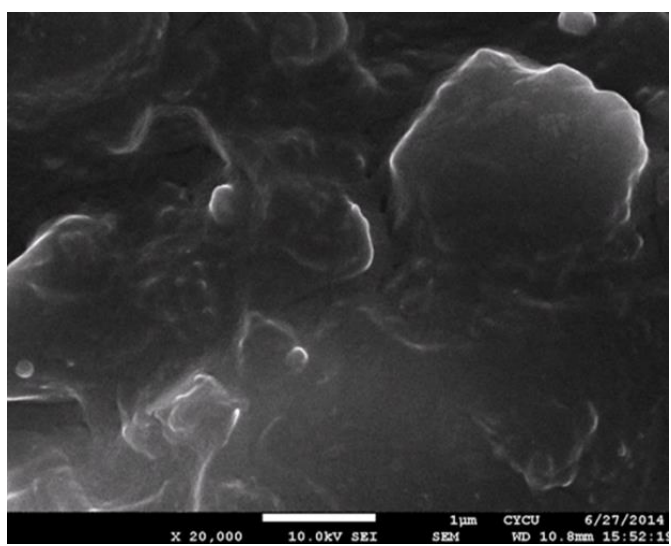

a

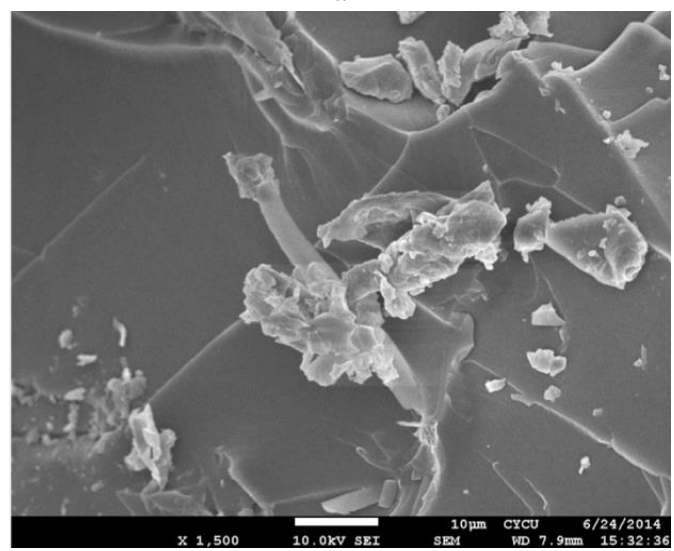

b

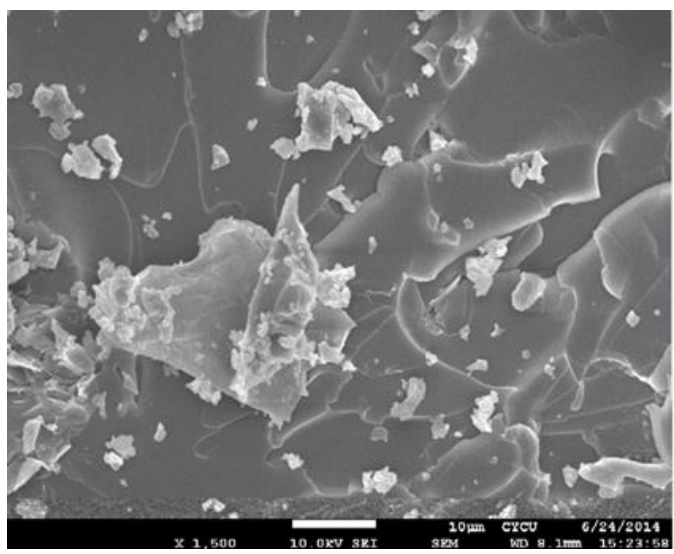

c

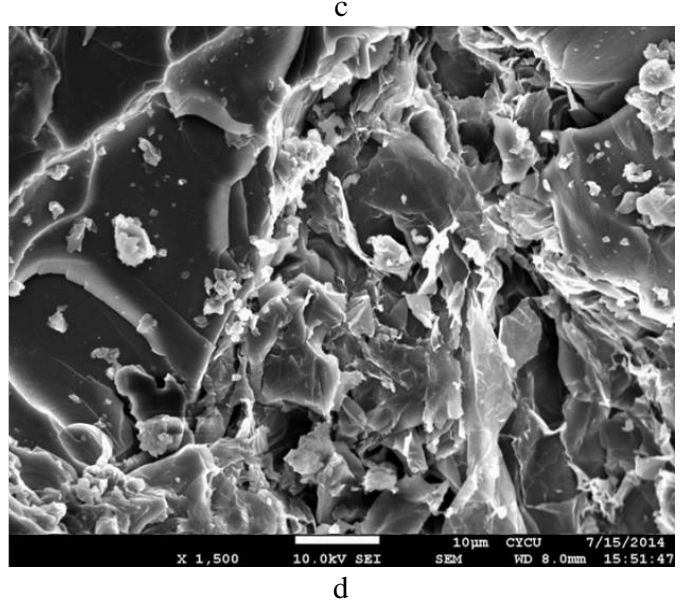

Fig. 8. SEM images of fractured surfaces of: a-neat epoxy; b-0.3 wt. $\%$ GNP; c-0.5 wt. $\%$ GNP; d-1.0 wt. $\%$ GNP 


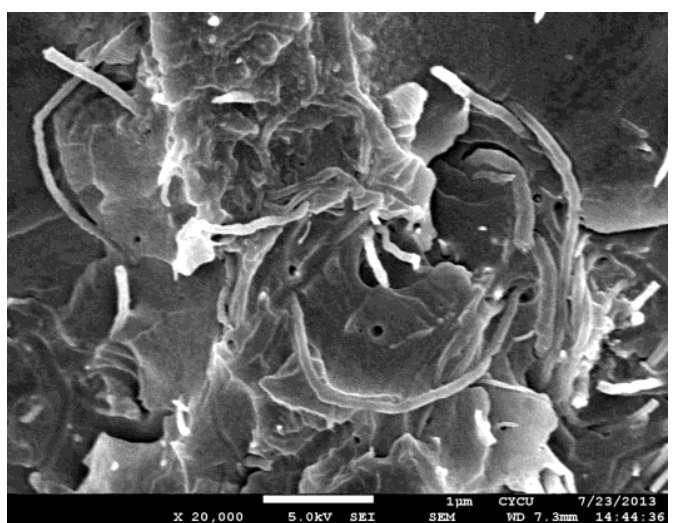

a

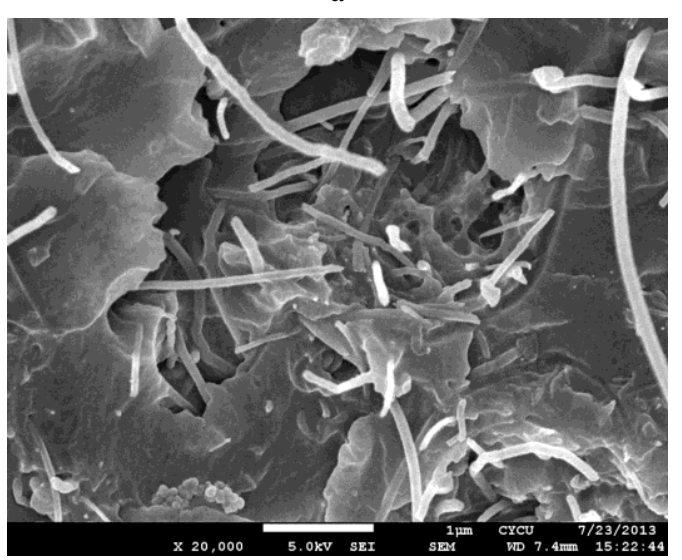

b

Fig. 9. SEM images of fractured surfaces of: a-0.3 wt.\% MWCNT; b - 0.5 wt.\% MWCNT

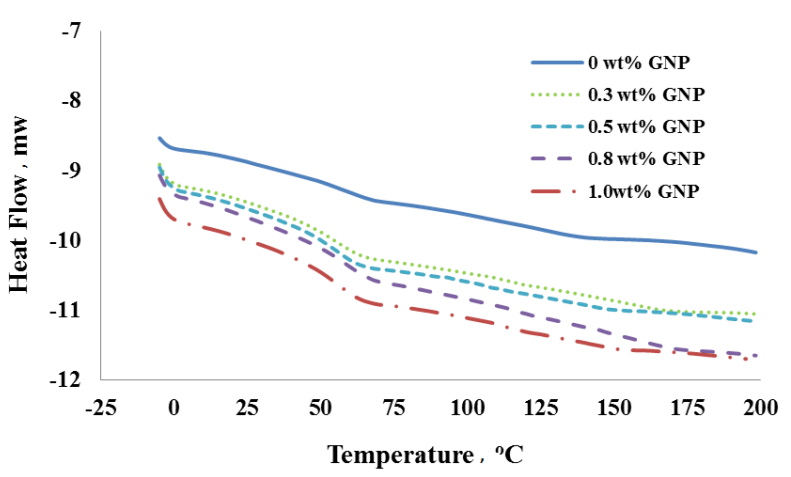

Fig. 10. DSC thermograms of GNPs/Epoxy nanocomposite with various GNP contents

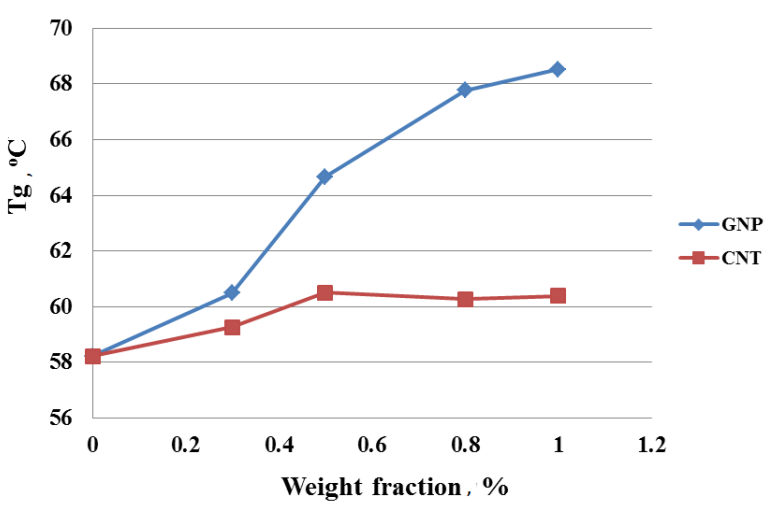

Fig. 11. DSC thermograms of MWCNTs/Epoxy nanocomposite with various MWCNT contents
The results of the glass transition temperature of MWCNTs/Epoxy and GNPs/Epoxy nanocomposites with various weight fractions are listed in Table 3.

Table 3. The averaged values of the glass transition temperature of MWCNTs/Epoxy and GNPs/Epoxy nanocomposites with various weight fractions

\begin{tabular}{|c|c|c|}
\hline \multirow{2}{*}{ Weight fraction } & \multicolumn{2}{|c|}{ Glass transition temperature $T_{g},{ }^{\circ} \mathrm{C}$} \\
\cline { 2 - 3 } & MWCNTs/Epoxy & GNPs/Epoxy \\
\hline $0 \%$ & $58.22 \pm 0.53$ & $58.22 \pm 0.53$ \\
\hline $0.3 \%$ & $59.26 \pm 0.62$ & $60.49 \pm 0.25$ \\
\hline $0.5 \%$ & $60.50 \pm 0.48$ & $64.67 \pm 0.36$ \\
\hline $0.8 \%$ & $60.27 \pm 0.24$ & $67.77 \pm 0.091$ \\
\hline $1 \%$ & $60.38 \pm 0.37$ & $69.18 \pm 0.53$ \\
\hline
\end{tabular}

It shows that the glass transition temperature of GNPs/Epoxy nanocomposite increases from $58.22^{\circ} \mathrm{C}$ to $69.18{ }^{\circ} \mathrm{C}$ as the weight fraction of GNP increases from $0 \%$ to $1 \%$ which is about $18.8 \%$ higher than that of the neat epoxy. This could be attributed to a large aspect ratio and strong interaction between graphene and the epoxy matrix, restricting the movement of the polymer chains. In contrast, the addition of MWCNTs on the epoxy exhibits a little effect on the glass transition temperature of the nanocomposite. As the weight fraction of the MWCNT increases from $0 \%$ to $1 \%$, the glass transition temperature increases from $58.22{ }^{\circ} \mathrm{C}$ to $69.18{ }^{\circ} \mathrm{C}$ which is only $3.7 \%$ higher than that of the neat epoxy. The comparison of the glass transition temperature between MWCNTs/Epoxy and GNPs/Epoxy nanocomposites for a variety weight fractions is shown in Fig. 12. It can be seen that GNPs perform significantly better than that of MWCNTs.

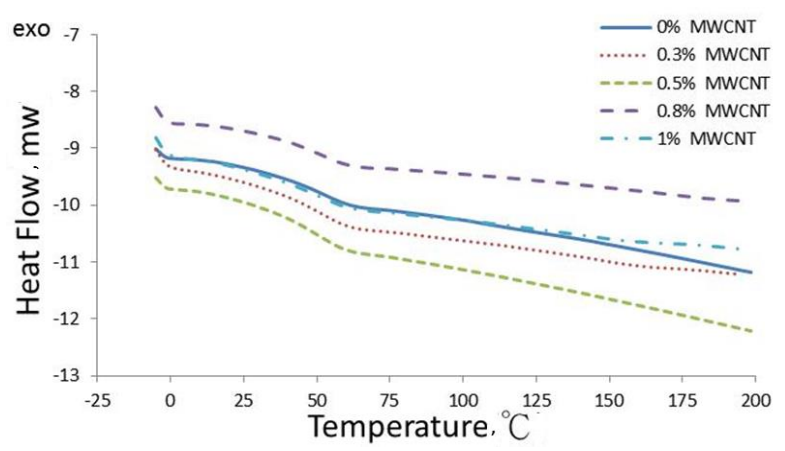

Fig. 12. Comparison of glass transition temperature between GNPs/Epoxy and MWCNTs/epoxy nanocomposites with various weight fractions

\section{CONCLUSIONS}

Two different types of nanocomposites were successfully prepared by incorporating GNPs and MWCNTs into epoxy matrix. The effects of GNPs and MWNCTs on the mechanical and thermal properties of the nanocomposites were studied. The elastic modulus of the GNPs/Epoxy nanocomposite was $40.7 \%$ greater than the neat epoxy as compared to $20.6 \%$ increase for MWCNTs/Epoxy nanocomposite at the same weight fraction of $1 \%$. The ultimate tensile strength of the neat epoxy was increased by $25.8 \%$ with 1 wt. $\%$ of GNPs compared to an increase of $21.3 \%$ for $1 \mathrm{wt} . \%$ of MWCNTs. The glass transition temperature of neat epoxy 
was increased by $18.8 \%$ with GNPs compared to an increase of $3.7 \%$ for MWCNTs. Experimental results demonstrate that the GNPs is superior to the MWCNT. The GNPs/Epoxy nanocomposites exhibit a significant improvement on the mechanical properties such as elastic modulus, yielding stress and ultimate tensile strength. The outperformance of GNPs over MWCNTs in terms of mechanical properties could be attributed to the high specific surface area resulting in an improvement of nanofiller-matrix adhesion and interlocking.

\section{Acknowledgments}

The authors would like to thank the Ministry of Science and Technology of R.O.C for the financial support under grant no. MOST 104-2221-E-155 -057-MY3.

\section{REFERENCES}

1. Lee, C., Wei, X.D., Kysar, J.W., Hone, J. Measurement of The Elastic Properties And Intrinsic Strength of Monolayer Graphene Science 5887 2008: pp. 385-388. https://doi.org/10.1126/science.1157996

2. Balandin, A.A., Ghosh, S., Bao, W.Z., Calizo, I., Teweldebrhan, D., Miao, F., Lau, C.N. Superior Thermal Conductivity of Single-Layer Graphene Nano Letters 8 2008: pp. $902-907$. https://doi.org/10.1021/n10731872

3. Bolotin, K.I., Siles, K.J., Jing, Z., Klima, M., Fudenberg, G., Hone, J., Kim, P., Stormer, H.L. Ultrahigh Electron Mobility In Suspended Graphene Solid State Communications 146 2008: pp. 351-355. https://doi.org/10.1016/j.ssc.2008.02.024

4. Chen, J.H., Jang, C., Xiao, S., Ishigami, M., Fuher, M.S. Intrinsic And Extrinsic Performance Limits Of Graphene Devices $\quad$ On $\quad \mathrm{SiO}_{2} \quad$ Nature Nanotechnology 3 2008: pp. 206-209. https://doi.org/10.1038/nnano.2008.58

5. Wang, X., Zhi, L.J., Mullen, K. Transparent, Conductive Graphene Electrodes For Dye-Sensitized Solar Cells Nano Letters 8 2008: pp. 323-327. https://doi.org/10.1021/n1072838r

6. Fowler, J.D., $\quad$ Allen, M.J., $\quad$ Tung, V.C., $\quad$ Yang, Y., Kaner, R.B., Weiller, B.H. Practical Chemical Sensors From Chemically Derived Graphene ACS Nano 3 2009: pp. $301-306$.

https://doi.org/10.1021/nn800593m

7. Wang, C.Y., Li, D., Too, C.O., $\quad$ Wallace, G.G. Electrochemical Properties of Graphene Paper Electrodes Used In Lithium Batteries Chemistry of Materials 21 2009: pp. 2604-2606. https://doi.org/10.1021/cm900764n

8. Wang, Y., Shi, Z.Q., Huang, Y., Ma, Y.F., Wang, C.Y., Chen, M.M., Chen, Y.S. Supercapacitor Devices Based on Graphene Materials Journal of Physical Chemistry C 113 2009: pp. $13103-13107$. https://doi.org/10.1021/jp902214f

9. Liu, X.D., Han, Y.D., Jing, H.Y., Wei, J., Xu, L.Y. Effect of Graphene Nanosheets Reinforcement On The Performance of $\mathrm{Sn}-\mathrm{Ag}-\mathrm{Cu}$ Lead-Free Solder Materials Science \& Engineering A 562 2013: pp. 25-32. http://dx.doi.org/10.1016/j.msea.2012.10.079

10. Liu, S., Yan, H., Fang, Z., Wang, H. Effect of Graphene Nanosheets On Morphology, Thermal Stability And Flame
Retardancy of Epoxy Resin Composites Science and Technology 90 2014: pp. 40-47.

http://dx.doi.org/10.1016/j.compscitech.2013.10.012

11. Heo, C., Chang, J.H. Polyimide Nanocomposites Based On Functionalized Graphene Sheets: Morphologies, Thermal Properties, And Electrical And Thermal Conductivities Solid State Sciences 24 2013: pp. 6-14.

http://dx.doi.org/10.1016/j.solidstatesciences.2013.06.012

12. Park, O.K., Kim, S.G., You, N.H., Ku, B.C., Hui, D., Lee, J.H. Synthesis And Properties of Iodo Functionalized Graphene Oxide/Polyimide Nanocomposites Composites: Part B 56 2014: pp. 365-371. http://dx.doi.org/10.1016/j.compositesb.2013.08.065

13. Moriche, R., $\quad$ Sanchez, M., Jimenez-Suarez, A., Prolongo, S.G., Urena, A. Electrically Conductive Functionalized-GNP/Epoxy Based Composites: From Nanocomposite To Multiscale Glass Fibre Composite Material Composites Part B 98 2016: pp. 49-55. http://dx.doi.org/10.1016/j.compositesb.2016.04.081

14. Dai, G., Mishnaevsky, L. Graphene Reinforced Nanocomposites: 3D Simulation of Damage And Fracture Computational Materials Science 95 2014: pp. 684-692. http://dx.doi.org/10.1016/j.commatsci.2014.08.011

15. Wan, Y.J., Tang, L.C., Yan, D., Zhao, L., Li, Y.B., Wu, L.B., Jiang, J.X., Lai, G.Q. Improved Dispersion And Interface In The Graphene/Epoxy Composites Via A Facile Surfactant-Assisted Process Composites Science and Technology 82 2013: pp. 60-68.

http://dx.doi.org/10.1016/j.compscitech.2013.04.009

16. Luong, N.D., Hippi, U., Korhonen, J.T., Soininen, A.J., Ruokolainen, J., Johansson, L.S., Nam, J.D., Sinh, L.H., Seppälä, J. Enhanced Mechanical And Electrical Properties of Polyimide Film By Graphene Sheets Via In Situ Polymerization Polymer 52 2011: pp. 5237-5242. https://doi.org/10.1016/j.polymer.2011.09.033

17. Zaman, I., Phan, T.T., Kuan, H.C., Meng, Q., La, L.T.B., Luong, L., Youssf, O., Ma, J. Epoxy/Graphene Platelets Nanocomposites With Two Levels of Interface Strength Polymer 52 2011: pp. 1603-1611. https://doi.org/10.1016/j.polymer.2011.02.003

18. Pontefisso, A., Mishnaevsky, L. Nanomorphology of Graphene And CNT Reinforced Polymer And Its Effect On Damage: Micromechanical Numerical Study Composites Part B 96 2016: pp. 338-349. http://dx.doi.org/10.1016/j.compositesb.2016.04.006

19. Zarasvand, K.A., Golestanian, H. Investigating The Effects of Number And Distribution of GNP Layers On Graphene Reinforced Polymer Properties: Physical, Numerical And Micromechanical Methods Composites Science and Technology 139 2017: pp. 117-126. http://dx.doi.org/10.1016/j.compscitech.2016.12.024

20. Spanos, K.N., Anifantis, N.K. Finite Element Prediction of Stress Transfer In Graphene Nanocomposites: The Interface Effect Composite Structures 154 2016: pp. 269-276. http://dx.doi.org/10.1016/j.compstruct.2016.07.058

21. Liu, Y., Hamon, A.L., Bai, J. Directly Measuring Interfacial Shear Strength Between Polymethyl Methacrylate And Graphene Nanoplatelets Materials Letters 182 2016: pp. $244-247$. http://dx.doi.org/10.1016/j.matlet.2016.06.120

22. Jangam, S., Raja, S., Maheswar Gowd, B.U. Influence of Multiwall Carbon Nanotube Alignment On Vibration Damping of Nanocomposites Journal of Reinforced Plastics and Composites 35 2016: pp. 617-627. https://doi.org/10.1177/0731684415626285 
23. Jangam, S., Raja, S., Hemachandra Reddy, K. Effect of Multiwalled Carbon Nanotube Alignment On The Tensile Fatigue Behavior of Nanocomposites Journal of Composite Materials 52 2018: pp. 2365-2374. https://doi.org/10.1177/0021998317745585

24. Sethi, J., Sarlin, E., Meysami, S.S., Suihkonen, R., Kumar, A.R.S.S., Honkanen, M., Keinänen, P., Grobert, N., Vuorinen, J. The Effect of Multi-Wall Carbon Nanotube Morphology On Electrical And Mechanical Properties of Polyurethane Nanocomposites Composites: Part A 102 2017: pp. 305-313. http://dx.doi.org/10.1016/j.compositesa.2017.08.014

25. Liang, J.Z. Effects of Graphene Nano-Platelets Size And Content On Tensile Properties of Polypropylene Composites At Higher Tension Rate Journal of Composite Materials 52 2018: pp. 2443-2450. https://doi.org/10.1177/0021998317746478

26. Bansal, S.A., $\quad$ Singh, A.P., $\quad$ Kumar, A., Kumar, S., Kumar, N., Goswamy, J.K. Improved Mechanical Performance of Bisphenol-A Grapheme Oxide
Nanocomposites Journal of Composite Materials 2018: pp. $2179-2188$.

https://doi.org/10.1177/0021998317741952

27. Zakaria, M.R., Kudus, M.H.A.,

Akil, H.M., Thirmizir, M.Z.M. Comparative Study of Graphene Nanoparticle And Multiwall Carbon Nanotube Filled Epoxy Nanocomposites Based On Mechanical, Thermal And Dielectric Properties Composites Part B 119 2017: pp. $57-66$. http://dx.doi.org/10.1016/j.compositesb.2017.03.023

28. Kostagiannakopoulou, C., Tsilimigkra, X., Sotiriadis, G., Kostopoulos, V. Synergy Effect of Carbon Nano-Fillers On The Fracture Toughness of Structural Composites Composites Part B 129 2017: pp. 18-25. http://dx.doi.org/10.1016/j.compositesb.2017.07.012

29. Martin-Gallego, M., Bernal, M.M., Hernandez, M. Verdejo, R., Lopez-Manchado, M.A. Comparison of Filler Percolation And Mechanical Properties In Graphene And Carbon Nanotubes Filled Epoxy Nanocomposites European Polymer Journal 49 2013: pp. 1347-1353. http://dx.doi.org/10.1016/j.eurpolymj.2013.02.033 